Araştırma Makalesi / Research Article

\title{
BİR İŞ ZEKASI UYGULAMASI VE BAŞARISININ DEĞERLENDİRILMESİ
}

\author{
Doğan YILDIZ*
}

\section{A BUSINESS INTELLIGENCE APPLICATION AND EVALUATION OF ITS SUCCESS}

\begin{abstract}
$\ddot{O} z$
Yöneticiler genellikle karar alırken öncelikle problemi net bir şekilde tanımlar, onunla ilgili model ve çözüm alternatiflerini belirler, ardından probleme en uygun çözüm önerisini bulmak için karşılaştırma yaparak çözüme ulaşırlar. Bu süreç içinde iş zekası uygulamalarının çok büyük bir önemi vardır. Bu uygulamalar, operasyonel seviyede, yönetsel seviyede ve stratejik seviyede bilgi sağlayıp karar vericinin doğru karar almasını sağlar. Bu çalışmanın amacı, bir işletmede uygulamaya alınan bir iş zekası çalışmasının başarısını belirli kriterler altında değerlendirmektir. $\mathrm{Bu}$ çalışmada öncelikle iş zekası ve başarısının değerlendirildiği çalışmalar hakkında bilgi verilmiş, sonrasında iş zekası kavramı açıklanmış ve araştırma kısmında ise bir işletmede iş zekası uygulaması ve bu uygulamanın başarısı üzerinde analizler yapılarak değerlendirmeler sunulmuştur. Sonuçta, işletmedeki iş zekası uygulamasının orta seviyede olduğu tespit edilmiştir.
\end{abstract}

Anahtar Kelimeler: İş Zekası, Veri Ambarı, Veri Madenciliği, Büyük Veri, Karar Destek Sistemleri.

\begin{abstract}
When making decisions, managers usually define the problem clearly, determine the model and solution alternatives related to it, then reach a solution by making comparisons to find the most appropriate solution to the problem. In this process, business intelligence applications are of great importance. These applications provide information at operational level, managerial level and strategic level and enable the decision maker to make the right decision. The purpose of this study is
\end{abstract}

* Dr., Türk Havacılık ve Uzay Sanayii (TUSAŞ), e-posta: dyildiz@tai.com.tr, https://orcid.org/0000-0002-0946-7251.

İntihal Taraması: Bu makale intihal taramasından geçirilmiştir.

Etik Beyan: $\mathrm{Bu}$ çalışmanın hazırlanma sürecinde bilimsel ve etik ilkelere uyulduğu ve yararlanılan tüm çalışmaların kaynakçada belirtildiği beyan olunur (Doğan Yıldız).

Atıf: Yıldız, D. (2021), Bir İş Zekası Uygulaması ve Başarısının Değerlendirilmesi, Abant Sosyal Bilimler Dergisi, 21(1), pp. 91-111. https://doi.org/10.11616/basbed.v21i60671.809529 
to evaluate the success of a business intelligence study implemented in a company under certain criteria. In this study, firstly, information was given about the studies in which business intelligence and its success were evaluated, then the concept of business intelligence was explained and in the research part, analyzes were made on the application of business intelligence and the success of this application and evaluations were presented. As a result, it has been determined that the business intelligence application in the enterprise is at a medium level.

Keywords: Business Intelligence, Data Warehouse, Data Mining, Big Data, Decision Support Systems.

\section{Giriş}

Günümüzde en büyük silah verinin anlamlandırılmasıdır. Bilgi sistemlerinin veya diğer sistem ve ekipmanların ürettiği veri artık belirli bir olgunluğa ulaşmıştır ve dolayısı ile bu veriden anlam çıkartarak kullanma aşaması çoktan gelmiştir. Dolayısı ile artık insanlar, veriden anlam çıkartarak insanları yönlendirebilmekte ve ona göre istedikleri doğrultuda hareket etmelerini sağlamaktadırlar. Veriye ne kadar hâkim olabiliyorsak ve onu kararlarımızı verirken kullanabiliyorsak o kadar başarılı ve aldığımız kararlar o kadar iyi olacaktır. Bu açılardan baktığımızda veri madenciliği ve verinin anlamlandırılması olarak gördüğümüz iş zekası uygulamaları artmaktadır ve ileride bilgi sistemlerinden ziyade bu tür sistem ve uygulamalar daha rağbet görecek ve kullanıcılar tarafından tercih edilecektir. Çünkü, insan karar alırken bir şeye kararını dayandırmak istemektedir. Bu tür sistem veya uygulamalar insanlara karar almaları için aradığı bilgiyi sunmaktadır.

Bireyler olsun işletmeler olsun bilgi sistemlerini çok yoğun bir şekilde kullanmaktadır. Bilgi sistemleri artık bu anlamda çok farklı veri barındırmaktadır. Kişisel bilgilerimizin yönetildiği sistemlerden şirketlerdeki kurumsal kaynak yazılımlarına, oradan da ekipmanlardaki gömülü yazılımlara kadar veriler farklı sistemlerde oluşturulmaktadır. $\mathrm{Bu}$ bakış açısı ile bakıldığında bu sistemlerde sürekli veri oluşmaktadır. Dolayısı ile oluşan veri artık sadece günlük yaşamda kullanılmasının yerine veriden anlam çıkarmak daha önemli hale gelmiştir. Buna göre gelecekteki kararlarımızın bu çıkarımlardan etkilenmesi kaçınılmadır. Tam bu aşamada artık iş zekası sistemleri önümüze çıkmaktadır. İş zekası uygulamaları yazılımların üretmiş olduğu verilerden anlam çıkarmak için bize yardımcı olmaktadir.

İş zekası uygulamaları, verilerin analiz edilmesi ile, olası risklerin görülmesini sağlamakta ve bunun sonucunda da, işletme yönetiminin başarısını arttırmaktadır. Bundan dolayı, iş zekası uygulamasının geliştirildiği işletmede, uygulamanın nasıl geliştirildiği, başarısı ve işletme 
yönetiminin bu uygulamadan nasıl faydalandığını görmek için bu çalışma yapılmıştır. Bu alandaki çalışmalara katkı sağlamak amacı ile, gerçek bir iş zekası uygulaması incelenmiş ve sonuçta araştırmacılara, bir iş zekası uygulamasının teoriden uygulamaya nasıl döküldüğü ve sonuçları gösterilmiştir. Çalışmanın sonucunda görülmüştür ki, işletmedeki iş zekası uygulaması orta seviyede bir uygulama olup üzerine ilave metriklerin eklenmesi ile yaygınlaştırılması gerekmektedir. Mevcut metrikler ile yapılan analizler işletme yönetimine çok büyük katkılar sağlamaktadır.

Bu çalışma kapsamında, öncelikle araştırma konusu ile ilgili olarak literatür araştırması sonuçları sunulmuş, ardından iş zekası kavramı ve altındaki yöntemler anlatılmış, sonrasında da ısıtma ile soğutma sistemleri satış ve satış sonrası hizmeti sunan bir işletmede belirli alanlarda devreye alınan iş zekası uygulaması hakkında bilgiler sunulmuş, son olarak ise bu uygulamanın başarısı belirli kriterler açısından değerlendirilmiştir.

\section{Literatür İncelemesi}

İş zekası terimi ilk olarak Luhn'un (1958) çalışması ile ortaya çıkmıştır. Bu çalışmada, bir iş zekası sistemi geliştirdiğini, bunun veri işleme olduğunu ve dışarıdan gelen veya içerde üretilen evrakların içindeki bilgilerin otomatik algılanarak ilgili kişilere yönlendirilmesinin otomatik yapılacağını aktarmıştır. Power (2007), iş zekasının ilk olarak, 1989 yılında Gartner grup'dan Howard Dresner tarafindan gerçeğe dayalı destek sistemlerindeki verileri kullanarak işletmede karar almayı geliştirmek için konsept ve metotlar setidir, şeklinde tanımlamıştır.

Simovits ve Forsberg (1995-1996) çalışmalarında, internette iş zekası ve bilgi savaşında ne kadar güvenlik önlemleri alınsa bile artık internetteki her türlü bilgiden farklı çıkarımlar yapılabileceğini aktarmışlardır. İnternet bilgi edinmek için farklı firsatlar sunmaktadır, ancak, sistemlere zarar vermeden bilgide manipülasyon yapılabilmekte ve bilgi kazanc1 sağlanabildiği ifade edilmektedir. Daş, Türkoğlu ve Poyraz (2006) web madenciliği ile ilgili olarak, bir sunucu üzerindeki erişim ham verilerinden genetik algoritma yöntemi ile istatistiki bilgi çıkarmışlardır. Buna göre üniversitedeki internet kullanımından en çok kullanılan akademik veri tabanı adresleri bulunmuştur. Bunun yanında çalışmayan sayfalar ve en çok kullanılan sayfalar şeklinde bilgilere de ulaşma imkanları olmuştur.

Matheus, Chan ve Shapiro (1993), veri tabanlarından bilgi keşfinin otomatik hale gelmesinin dünyadaki sağlık sistemindeki verinin üstel olarak artmasından dolayı büyük bir önem kazandığını aktarmışlardır. Veri tabanlarının dinamik olması, tamamlanmamış, gereksiz, gürültülü, seyrek, çok büyük ve dinamik veri içermelerinden dolayı bilgi keşif sistemlerinin 
zorlayıcı problemler ile karşı karşıya kaldıklarını görmekte olduğumuzu vurgulamışlardır. Çalışmalarında bu problemlerin üstesinden gelecek bazı tekniklere yer verdiklerini ve bunun yanında bir sistem tasarladıklarını aktarmışlardır. Koyuncugil ve Özgülbaş (2009), veri madenciliği ve iş zekası yöntemleri konularında çalışmalarında bilgi vermişlerdir. Uygulama kısmında ise ülkemizdeki sağlı sektöründe öncelikli konu ve sorun alanları ile ilgili veri madenciliği uygulamaları ile ilgili örnekler sunmuşlardır. $\mathrm{Bu}$ doğrultuda sağlık sektörü için kronik hastalıkların önceden veri madenciliği ile öngörülmesi, klinik karar destek sistemleri geliştirilmesi, laboratuvar testleri için hata ve suistimallerin belirlenmesi gibi farklı konularda 12 adet önerilerde bulunmuşlardır.

Chen, Chiang ve Storey (2012), iş zekası ve analitiğinin gelişim sürecini üç aşamaya bölmüşlerdir. İlk aşaması, veri tabanı yönetim sistemleri ve yapılandırılmış veri ile işlem yapılan aşama, ikinci aşaması web tabanlı ve yapılandırılmamış verinin olduğu web tabanlı uygulamalar ve üçüncü aşaması ise mobil ve sensör tabanlı uygulamaların olduğu aşama olarak aktarmışlardır. Çalışmada, beş alanda bu kavramların büyük etkileri olacağı aktarılmıştır. Bu beş alan; 1) e-ticaret ve piyasa istihbarat1, 2) e-devlet ve politika 2.0,3) bilim ve teknoloji, 4) akıllı sağlık ve esenlik 5) güvenlik ve kamu güvenliğidir. Ayrıca, çalışma kapsamında iş zekası ve analitiği ile ilgili (büyük) veri analizi, metin analitiği, web analitiği, ağ analitiği, mobil analitik ile ilgili teknolojik gelişmelerin olacağını ifade etmiş̧lerdir. Ayrıca, Lim, Chen ve Chen (2013), bu konuda araştırma yönü olarak üç farklı yönü tariflemişlerdir. Bunlar; 1) Büyük veri analitiği, 2) Metin veri analitiği, 3) A $\breve{g}$ verisi analitiğidir. Aslında önerinin yapıldığı yıla bakıldığında bu gelişmeler günümüzde yaşanmaktadır. Hem büyük veri hem metin verisi hem de ağ verisi üzerinde analizler yapılarak farklı desen ve davranış şekilleri ortaya konulmaktadır. Bu tür çalışmalara ileriki aşamalarda daha çok göreceğiz. Büyük veri, ilk 2000'li yıllarda ortaya çıktığında İngilizce "V" harfi ile başlayan 3 kelime ile karakteristiği tanımlanmıştır. Bunlar, Variety (Çeşitlilik), Velocity (Hız), Volume (Veri Büyüklüğü) şeklindedir. Daha sonraları farklı karakteristikler de buna eklenmiştir. Metin veri analitiği, metin veri üzerinden anlamlı veriler çıkarmak amacı ile kullanılmaktadır. A $\breve{g}$ verisi analitiğine örnek olarak günümüzde yaygın olarak kullanılan sosyal medya üzerinden paylaştığımız bilgiler üzerinde bir çeşit analizler yapılarak anlamlandırılabilmektedir. Bunun yanında çalışmanın sonucunda akademi dünyası ile endüstri dünyasının bu tür çalışmalarda daha çok bir araya gelerek araştırmaları derinleştirecek ve teknoloji transferi sağlanacaktır. Çelebi ve Çakmak (2019), Analitik Hiyerarşi Prosesi yöntemi ile ETL kalite değerlendirmesini ISO 25010 kalite modelini kullanarak 1) fonksiyonel uygunluk, 2) kullanılabilirlik, 3) uyumluluk, 4) performans etkinliği, 5) güvenlik, 6) taşınabilirlik kriterleri 
ile beş firmanın ürününü değerlendirmişlerdir. Sonuç olarak, fonksiyonel doğruluk kriterini en önemli kriter olarak çalışma sonucunda ortaya koymuşlardır. Ardından kullanılabilirlik ve üçüncü sırada ise uyumluluk gelmektedir.

Şekil 1: İş Zekası Sitemlerinin Ana Bileşenleri

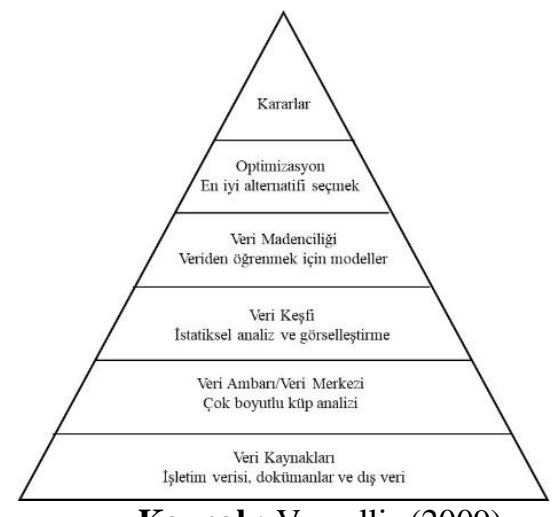

Kaynak: Vercellis (2009)

İş zekası uygulamalarına bakıldığında, işletme yöneticilerinin karar alabilmeleri için ilgili verinin kaynağından çıkıp karar aşamasına kadar Şekil 1'de de yer aldığg üzere farklı adımlardan geçtiği görülmektedir. Her adım kendi içinde büyük öneme sahiptir ve her adımda yapılacak olan bir yanlışlık, kararı yanlış almamıza ve işletmeyi kötü duruma düşürmemize sebep olabilecektir. Bundan dolayı, oluşturulacak olan iş zekası uygulamalarının kurgulanması aşamasından sonuna kadar zaman, kalite, performans üçgeninin çok iyi bir şekilde yönetilmesi gerekmektedir.

İş zekası kapsamında veri madenciliği hem işletme içindeki süreçlerde verilerin anlamlandırılması hem de bunun yanında işletme dışında çok farklı sektörlerde kullanılabilmektedir. Bunlardan, Dondurmacı ve Çınar (2014), İstanbul Menkul Kiymetler Borsasından elde ettikleri veriler ile veri madenciliği modelleri içinde tahmin edici model olarak ele alınan sınıflandırma yöntemini uygulamışlardır. Çalışmalarında analize dâhil ettikleri niteliklerin anlamlı olmayanlarını elemek amacı ile farklı modeller kullanarak istatiksel olarak anlamlı olmayanları elemişlerdir. Sonuçta, menkul kıymetlerin fiyatlarına etki eden ortalama ve üstel ortalama fiyatlarının etkili olduğunu görmüşlerdir. Ayrıca, Terzi (2019), Hastalık Teşhisi ve Tanısına Yönelik Uygulamalar ve İlaçlara Yönelik Uygulamalar konularında bilgiler sunmuştur. $\mathrm{Bu}$ çalışmada, veri madenciliği uygulamalarının sağlık çalışanlarına verileri yorumlamada yardımcı bir araç olacağı sonucuna varmışlardır. Bu çalışmaların yanısıra, büyük veri anlamında en büyük veriler kamu kurumlarının elinde yer almaktadır. $\mathrm{Bu}$ 
kapsamda kamu da büyük veri ve iş zekası çalışmaları başlamış olup ilerleyen zamanda bu çalışmalar giderek daha da hız kazanacaktır. Howson (2014), iş zekası uygulamalarının yönetimi ve kontrol, performans iyileştirme, operasyon seviyesi, süreç iyileştirme, müşteri hizmetlerini iyileştirme, spor ve günlük hayattaki işler gibi birçok alanda kullanılabileceğini açıklamıştır. Bunun yanında iş zekası uygulamalarının başarı veya başarısızlığının nasıl ölçüleceği ile ilgili bilgiler sunmuştur. Gültekin ve Biroğul (2020), yapmış oldukları geliştirmenin sonucunda iletişim, bilgi paylaşımı ve kişisel verimliliğin arttığını, maliyet avantajı sağlandığını, yapısal verilerin yaygın kullanımının arttığını ve kullanıcıların iş zekası çözümlerine olan güvenlerinin arttığını açıklamıştır. Çetin ve Tanrı̈ver (2020), kurumun personel bilgi sisteminde statik bir şekilde oluşturulan ve dinamik analiz yapılamayan raporlar ve istatistiklerin yerine iş zekası ve veri madenciliği çözümleri ile kullanıcıların dinamik bir şekilde analiz yapabileceği personel karar destek sistemi oluşturmuşlardır.

\section{Yöntem}

İhtiyacın doğru iş zekası teknikleri ile giderilmesi çalışmanın başarısı için çok önemlidir. Farklı analiz ihtiyaçları için farklı teknikler kullanıldığ1 Şekil 2'de görülmektedir. Dolayısı ile işletmelerin ihtiyaçlarını net bir şekilde ortaya koyması ve ardından bu ihtiyacı hangi teknik ile çözümleyeceğini belirlemesi gerekmektedir.

Şekil 2: Farklı Analiz İhtiyaçları için Farklı Teknikler

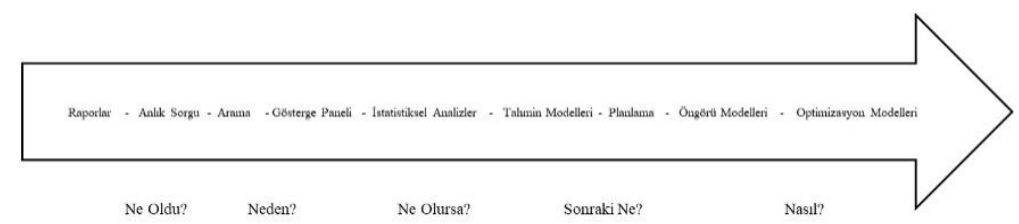

Kaynak: Loshin (2013)

Fayyad, Shapiro ve Smyth (1996), veri tabanlarındaki her sektörde yer alan hızlı büyümeden dolayı analizleri artık bir insanın yapmasının zor olduğunu ve bunun için otomatik sistem geliştirmenin öneminden bahsetmişlerdir. $\mathrm{Bu}$ kapsamda gerçek dünyada Boeing 737 uçağındaki problemlere teşhis konulması ve tahmin edilmesi, kredi kartı dolandırıcılığının kredi kartı işlemlerini izleyerek bulunması, bir şirketin uzman sistemler, yapay sinir ağları ve genetik algoritmayı kullanarak yatırım yapması, pazarlama amaçlı analizler, telekomünikasyon alanındaki çalışmalar gibi farklı çalışmalardan örnekler vermişlerdir. Bunun yanında Şekil-3' de görülen veri tabanlarından bilgi keşfi sürecini dokuz basamakta aktarmışlardır. Bunlar; 1) Uygulamanın geliştirileceği alan ve müşteri gözüyle bilgi keşif süreci 
hakkında bilgi sahibi olmak, 2) Hedef veri setinin geliştirilmesi, 3) Veri temizliği ve ön proseslerin yapılması, 4) Veri indirgeme ve projeksiyon, hedefe göre verideki faydalı özellikleri bulma ve veride gerekli düzenlemeleri yapma, 5) Bilgi keşif sürecinin hedefleri ile veri madenciliği metotlarını eşleştirme, örneğin; özetleme, sınıflandırma, regresyon, kümeleme gibi, 6) Araştırma analizi ve modeli ile hipotezin seçimi, veri madenciliği algoritmasının ve metodunun seçimi, 7) Veri madenciliği, ilgi alanımızdaki deseni araştırmak, sınıflandırma kuralları ve ağacı, regresyon ve kümeleme analizi, 8) Veri madenciliği sonuçlarını analiz etmek ve yorumlamak, adımlardan bir veya yedi arasındaki herhangi bir adıma geri dönmek, 9) Bulunan bilgiye göre hareket etmek.

Şekil 3: Veri Tabanlarından Bilgi Keşif Süreci

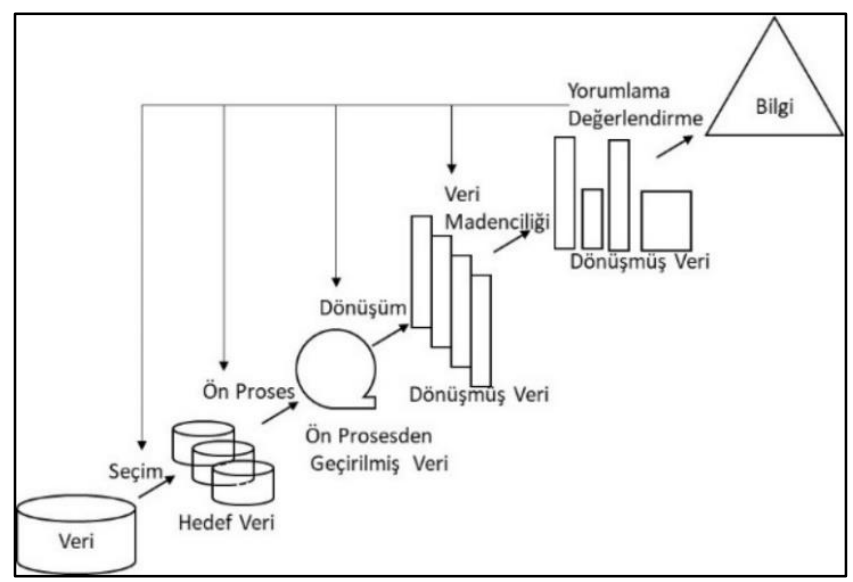

Kaynak: Fayyad, Shapiro ve Smyth (1996)

Bilgi, veri tabanında durduğu sürece işimize yaramamaktadır. Sadece veri tabanı sorgulandığında ilgili konu hakkında bize var olan bilgileri getirmektedir. İşte bu aşamada Şekil 3'te görüleceği üzere, bu veri içinden bilgiyi çıkarmak gerekmektedir.

Veriden bu bilgiyi çıkarabilmek için iş zekası yöntemlerinin veriyi okudukları temel olan veri ambarlarının kurulması gerekmektedir. Veri ambarları bu süreçte veri madenciliği, anlık analizler ve karar destek işlemleri için gerekli olan verinin işletimde çalışan farklı sistemlerden alınıp, temizlendiği ve saklandığı veri tabanlarıdır. 
Şekil 4: - Veri Ambarı Oluşturma Süreci

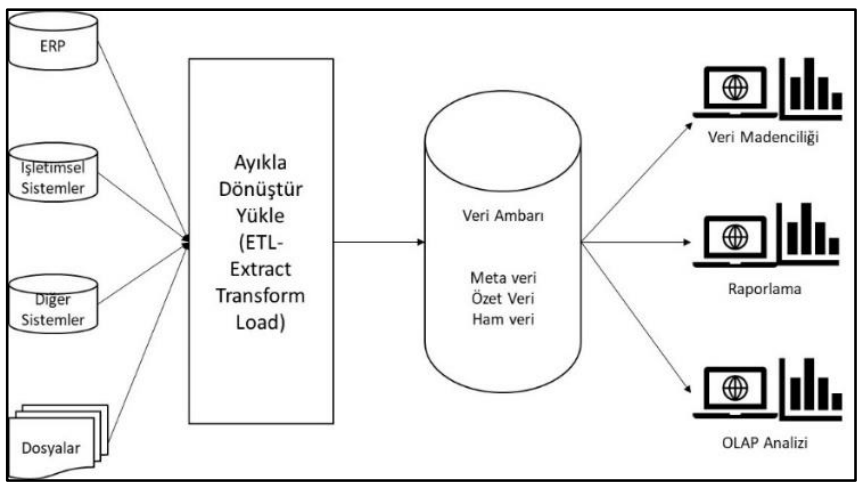

Kaynak: www.datawarehouse4u.info/

Veri ambarı ile ilgili sürecin nasıl çalıştığı Şekil 4'de aktarılmaktadır. Buna göre farklı ortamlardan çekilen veriler ayıklanıp, dönüştürülüp veri ambarına yüklenmektedir. Daha sonra da veri ambarından bu veriler farklı analizler veya raporlama amaçlı kullanılabilmektedir. Veri ambarındaki veri tabanları herhangi bir ilişkisel veri tabanı olabilir. Bu veri tabanları adhoc veri tabanı sorgulamalarını (son 3 ay içinde mağazadan meyve almış ve bunun yanında makarna almış ve yaşları 35 ile 45 arasında olan bay ve bayan müşteriler gibi) hızlı bir şekilde işleyip cevap verecek yapıda olmalıdır. Şekil 4'teki gösterime ilave olarak verinin sunum katmanı olan veri madenciliği, raporlama gibi katmandan önce veri ambarı ile sunum katmanı arasında özel amaçlar için orta seviye katman olabilir. Bunlar, OLAP sunucusu, veri madenciliği sunucusu, rapor sunucusu, arama motoru sunucusu şeklinde sıralanabilir. OLAP sunucuları, çok boyutlu veri analizini yapabilmek için ve iş zekası operasyonları olan filtreleme, toplama, detaya inme ve pivot işlemleri gibi işlemleri yapmamızı sağlamaktadırlar. Bunun yanında günümüzde gündemde olan "in memory" iş zekası işlemlerinin de yapılabilmesi gerekmektedir. En ön katman olan sunum katmanında ise arama motorları, raporlar, veri madenciliği ile ilgili işlemlerin yürütüldüğü ön yüzler, performans yönetimi kapsamında takip edilen dashboard'lar vb. farklı uygulamalar yer almaktadır. Ayrıca son zamanlarda önemi artarak gündemde olan web analiz araçları ve ayrıca mobil iş zekası uygulamaları da bu katmanda yer almaktadır. 
Şekil 5: Çok Boyutlu Veri

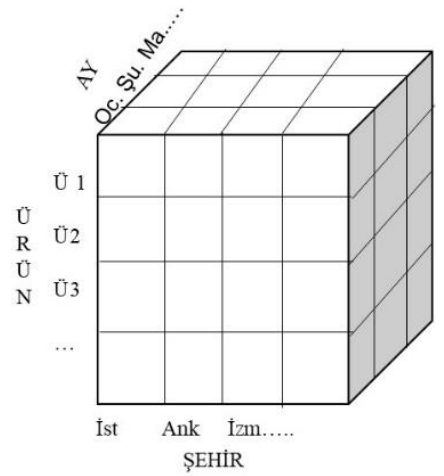

Kaynak: Han, Kamber ve Pei (2012)

Yukarıda açıklanmış olan OLAP sunucusu bu kapsamda Şekil 5'te gösterimi yer alan çok boyutlu veri üzerinde OLAP işlemlerini (filtreleme, toplama, detaya inme ve pivot işlemleri vb.) gerçekleştirmektedir. Bellekte (In memory) iş zekası uygulamaları ise veriyi veri tabanı yerine hafizada tutarak veriye hızlı bir şekilde ulaşma imkânı sağlamaktadır.

Veri merkezi (data mart) belirli bir bölüme veya gruba ait olarak oluşturulmuş verilerdir. Bu kapsamda sadece finans bölümüne, pazarlama veya üretim bölümüne ait veri merkezleri olabilir.

Bazı durumlarda veri ambarına veriyi aktarmadan gerçek zamanlı veri üzerinden iş zekası uygulamalarını çalıştırmak gerekmektedir. Bunlara gerçek zamanlı iş zekası veya gerçek zamana yakın iş zekası denilmektedir. Bazen de bu tür iş zekası uygulamaları işletimsel iş zekası veya anında iş zekası olarak da adlandırılmaktadır. Bununla ilgili olarak Şekil 6'da görüleceği üzere, iş ile ilgili olayın olması ile verinin saklanması arasındaki kısmı "veri gecikmesi", verinin saklanması ile bilginin sunulması arasındaki kısmı "analiz gecikmesi" bilginin sunulması ile aksiyon alınması arasındaki geçen zaman da "karar gecikmesi" şeklinde tanımlanmaktadır. Aslında iş zekası uygulamaları bazı durumlarda anlık olarak bazı bilgileri sunmaları gerekirken bazı durumlarda anlık yerine arada zaman farkı olarak da sunulmasında sakınca yoktur. İş zekası uygulamasının kurulduğu sürece göre değişiklik arz etmektedir. Zaman arttıkça değer azaldığı için ihtiyacın iyi analiz edilmesi gerekmektedir. Veri ve analiz gecikmeleri bir şekilde teknolojik çözümler ile bir noktaya kadar çözümlenebilmektedir. Ancak karar gecikmesi süreç ile ilgilidir ve bu konuda süreç değişimi veya yöneticilerin bakış açılarını değiştirmeleri gerekmektedir. Aslında bu tartışmalar İngilizce "real-time" anında (o an) ve "right-time" zamanında 
(o zaman) kelimeleri ile karşılaştırılabilir. Aslında ihtiyaç olan anında değildir. Zamanında veri ihtiyacının giderilmesi durumunda iş zekası uygulamaları görevini yapmış olacaktır. Zamanında olması bazı durumlarda anında olmasını gerektirebilir. Dolayısı ile her zaman anında dememek, ihtiyaca göre hareket etmek en doğru yaklaşım olacaktır. Genellikle operasyonel seviyede anlık iş zekası uygulaması yapılırken yönetsel seviyede ise stratejik kararlar alınacağı için anlıktan ziyade geleneksel iş zekası uygulamaları yapılmaktadır.

Şekil 6: Aksiyon Zamanının Bileşenleri-Üç Tip Gecikme

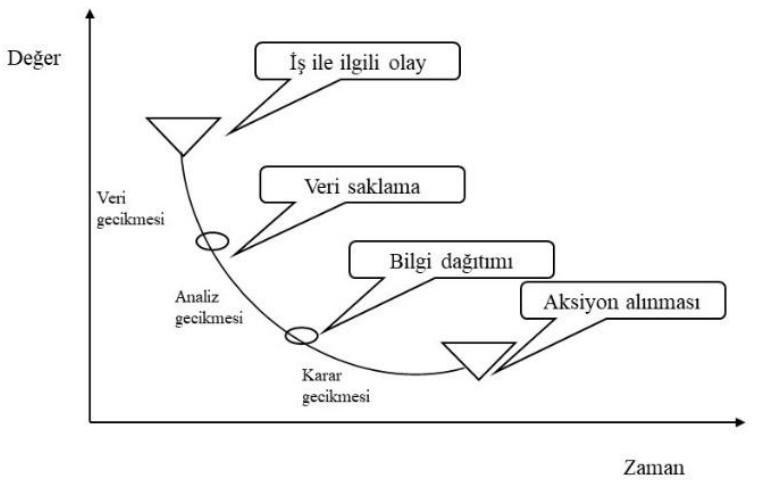

Kaynak: Hackathorn (2004)

Kurumsal arama motorları da bir çeşit iş zekası uygulamalarıdır. Bu motorlar kurumdaki web sayfasından, veri tabanından, e-postalardan verileri konfigürasyon verilerine göre sorgulama motoru ve indeks motoru üzerinden arama sonuçlarını getirmektedir.

Codd, Codd ve Salley (1993), çevrim içi analitik işleme (On-Line Analytical Processing) (OLAP) adlı çalışmalarında OLAP kavramını açıklamışlar ve bununla ilgili olarak kuralları belirlemişlerdir.

OLAP genelde Çevrimiçi İşlem İşleme (OLTP-On Line Transactional Processing) sistemlerinden farklı olarak verinin analiz edilmesi durumunda analistler tarafindan kullanım amacı ile verinin OLTP sistemlerinden ayrıştırılması ve çok boyutlu veri analizi için kullanılmasını tariflemektedir. OLTP ise günlük olarak kullandığımız veri tabanlarını ifade etmektedir. Her iki ortamın farklılıkları Tablo 1'de sunulmuştur. 
Tablo1: OLTP ve OLAP Sistemlerinin Farkları

\begin{tabular}{|l|l|l|}
\hline Karakteristik & OLTP & OLAP \\
\hline Oynaklık & Dinamik veri & Statik veri \\
\hline Güncel & Sadece güncel veri & Güncel ve geçmiş veri \\
\hline Zaman boyutu & Örtük ve şimdiki & Açı ve değişken \\
\hline Ayrıntı düzeyi & Detaylı veri & Toplu ve birleştirilmiş veri \\
\hline Güncelleme & Sürekli ve düzensiz & Periyodik ve düzenli \\
\hline Aktiviteler & Tekrarlayan & Öngörülemez \\
\hline Esneklik & Düşük & Yüksek \\
\hline Performans & $\begin{array}{l}\text { Yüksek, sorgu başına birkaç } \\
\text { saniye }\end{array}$ & $\begin{array}{l}\text { Belki, komplike sorgular için } \\
\text { belki düşük }\end{array}$ \\
\hline Kullanıcılar & Çalışanlar & Bilgi çalışanları \\
\hline Fonksiyonlar & Operasyonel & Analitik \\
\hline $\begin{array}{l}\text { Kullanım } \\
\text { amacı }\end{array}$ & İşlemsel & $\begin{array}{l}\text { Karmaşı sorgular ve karar } \\
\text { destek }\end{array}$ \\
\hline Öncelik & Yüksek performans & Yüksek esneklik \\
\hline Metrikler & İşlem oranı & Etkili yanıtt \\
\hline Boyut & Megabytes'dan gigabytes'a & Gigabytes'dan terabytes'a \\
\hline
\end{tabular}

Kaynak: Vercellis (2009)

Veri madenciliği ise veri ambarı veya farklı ortamlardaki veriden farklı metotları kullanarak desen çıkarmaktır. Bu anlamda dört farklı yöntem vardır. Bunlar;

1. Kümeleme

2. Sinıflandirma

3. Tahmin

4. Bağlantı kurma (örüntü)

$\mathrm{Bu}$ yöntemlerin altında çok farklı teknikler yer almaktadır. Çalışma yapılacak olan konuya göre bu tekniklerden biri veya birkaçı kullanılabilir. Bazı araştırmacı ve uygulayıcılar tarafından veri madenciliği çoğu zaman istatistiksel analizler ile karşılaştırılmaktadır. Bu kapsamda Emre ve Selçukcan Erol (2017), veri analizinde istatistik mi veri madenciliği mi? adlı çalışmalarında benzerlik ve farklılıklarını ortaya koymuşlardır. En büyük farklılıkları, veri madenciliği çalışmalarının büyük veri ve çok fazla değişken ile yapılması, veri setinin tamamı ile çalışılması, tümdengelim yaklaşımı olması ve bilgisayar yardımı ile tüm çalışmaların sürdürülmesi şeklinde açıklamışlardır.

Analiz yapılan verilerin saklandığı veri tabanlarının yapısına bakacak olursak, iş zekası uygulamaları çok boyutlu veri tablolarını okuyup işlem yapmaktadır. Bu tablolar gerçek (fact) ve boyut (dimension) tablolarından 
oluşmaktadır. Gerçek tabloları, kar tanesi veya yıldız (star) şeması şeklinde oluşturulan bu şemaların ortasında yer almaktadır. Boyut tabloları ise buna bağlı şekilde yer almaktadır. Gerçek tablosunun tek başına bir anlamı yoktur. Bu tablo, boyut tabloları ile beraber anlam ifade etmektedir. Boyut tabloları ise gerçek dünyadaki verileri, ölçümleri ve metrikleri tutan tablolardır. Kar tanesi şeması, yıldız şema gibidir ancak kar tanesi şemasındaki boyut tabloları normalize edilmiştir. Yıldız şemada bunlar normalize değildir.

Lönnqvist ve Pirttimäki (2006), iş zekasına yatırım ve bunun işletmeye kazandırdığının nasıl ölçülebileceği ile ilgili yatırımın ölçülmesinin getirisinin ölçülmesinden daha kolay olduğunu aktarmıştır. Buna göre aslında bu tür yatırımların getirilerinin görünmez olduğu ve ölçülmesinin çok zor olduğu ifade edilmiştir. Örneğin zamanında bilgiye erişim ve kalite gibi kavramların görünmez olmalarından dolayı ölçümleri zor olduğu söylenmiştir. Bunun yanında yatırımın geri kazanım oranının kullanılabileceği veya iş zekasının karara ne kadar katkısının olduğunu belirleyip ona göre kazancının hesaplanabileceği aktarılmıştır. Bununla ilgili olarak her firmanın farklı önermeleri ve modeli olduğu ve ona göre geri kazanımın ölçülebileceği söylenmiştir. Değerlendirme için iş zekası başarı modelinde direkt ve endirekt etki yaklaşımının uygulanabileceğini, direkt etki kapsamında objektif olarak iş zekasının katkılarının ölçülmesini, subjektif olarak ise yöneticilerin değerlendirmelerinin alınabileceği aktarılmıştır. Bunun yanında endirekt yaklaşım kapsamında ise objektif ölçüm olarak veri tabanı kullanımına bakılabileceği subjektif olarak ise kullanıcılar arasında kullanım anketi yapılabileceği açıklanmıştır.

\section{Uygulama}

Bilgi teknolojileri proje fikirlerinden birçoğu reddedilerek konsept olarak kalmakta veya yönetim seviyesinde bloke olmaktadır. Uygulamaya geçenlerin başarı şansı çok riskli olmakta veya bazıları kapasitenin altında kullanılmaktadır. Dünya Çapında Pazar Payı: Analitik ve İş Zekası (2020) Gartner raporuna göre iş zekası uygulamaları üst yönetim tarafından hala çok tercih edilmekte ve bu konudaki yatırımlar sürekli artmaktadır. İş zekası uygulamalarını tedarik etmek onu uygulamaya almaktan çok daha kolaydır. Asıl sorun bu tür sistemleri başarılı bir şekilde uygulamaya almakta yatmaktadır.

Eskiden iş zekası uygulamaları, sadece üst yönetim tarafından stratejik anlamda kullanılmak üzere geliştirilmektedir. Ancak şu zamanlarda bu artık değişime uğramış ve iş zekası uygulamaları hem taktik hem de operasyonel seviyede kullanılmaya başlanmıştır. 
Yeoh ve Popovic (2015) yapmış oldukları kritik başarı faktörlerinden anladıklarımızı, iş zekası sistemlerinin uygulamaya alınmasına uzatılması çalışmalarında Yeoh ve Koronios'un (2010) yapmış oldukları iş zekası sistemleri için kritik başarı faktörleri adlı çalışmasından alarak standart bir iş zekasının uygulamaya alınması esnasında diğer bilişim sistemlerinin, örneğin kurumsal kaynak planlamasında olduğu gibi, uygulamaya alınması esnasında görüldügü gibi teknolojik, organizasyonel ve süreçsel hususların içinde olduğu çok yönlü bir husus olduğunu vurgulamışlardır. Asıl çalışmanın içeriği ise, iş zekası uygulamalarının hayata geçirilmesi esnasında kritik başarı faktörlerinin neler olduğu ile ilgili bir yapıyı ele almışlardır. $\mathrm{Bu}$ kapsamdaki kritik başarı faktörleri ve başarı kriterleri aşağıda yer almaktadır.

Kritik Başarı Faktörleri.

1. Organizasyon: a) Yönetim desteği ve sponsorluğunun taahhüt edilmesi, b) Açık vizyon ve çok iyi tanımlanmış iş kuralı

2. Süreç: a) İş merkezli şampiyonlar ve dengeli takım kompozisyonu b) İş odaklı ve tekrarlayan geliştirme yaklaşımı, c) Kullanıcı odaklı değişim yönetimi

3. Teknoloji: a) İş odaklı, ölçeklenebilir ve esnek teknik altyapı b) Sürdürülebilir veri kalitesi ve bütünlük

Başarı Kriterleri:

1. Altyapisal performans: a) Sistem kalitesi b) Bilgi kalitesi c) Sistem kullanımı

2. Süreç performansı: a) Bütçe, b) Zaman takvimi

$\mathrm{Bu}$ yapıya göre farklı sektörlerde yer alan yedi iş zekası uygulayan şirketi incelemişler ve kritik başarı faktörlerini uygulayan firmaların iş zekası uygulamalarına, çok büyük direkt ve olumlu etkisinin olduğunu görmüşlerdir. Bu şirketlerden kritik başarı faktörlerine göre beş tanesindeki uygulamanın başarılı, bir tanesinde kısmen başarılı ve bir tanesinde ise başarısız bir uygulama olduğunu aktarmışlardır.

Kritik başarı faktörleri ile ilgili olarak benzer bir çalışmayı Eder ve Koch (2018) yapmıştır. Bu çalışmada ise öncelikle literatür çalışmalarını incelemişler ve buna göre 28 farklı kritik başarı faktörünü listelemişlerdir. Bunun yanında uzman kişiler ile de bir anket yapmışlar, bu anketten de bir kısmı literatür çalışması içinde olanlar da olmak üzere toplam 26 farklı faktör ile karşı karşıya kalmışlardır. Bunlar; kolay uygulama/prototipleme, yönetim desteği, kullanıcıyı dahil etme, veri kalitesi, diğer sistemler ile uyum, proje hedefleri ve vizyon, bilgi danışma, kullanıcıları eğitme, veri entegrasyonu, proje bütçesi, problemin tanımı, kaynaklar, proje yönetimi, 
değişiklik yönetimi, kullanılan altyapı/teknoloji, kalite güvence/test, başarı faktörlerinin tanımı, etkilenen bölümler ile koordinasyon, kullanılabilirlik, sistem performansı, diğer sistemlerden bağımsız çalışabilmesi, uygulayan bölüm, iş süreçleri, iş ihtiyaçları, iş zekasının bilgi teknolojilerine uyumu dur. Bu faktörleri organizasyon, teknoloji ve süreç şeklinde üç ana grup altında toplanabileceğini de çalışmalarında aktarmışlardır.

Elbashir, Collier ve Davern (2008) iş zekası sistemlerinin süreç düzeyinde performans etkilerini ölçmek için bir sistem geliştirmişlerdir. Aynı zamanda, organizasyonel seviye performans ile iş süreci seviyesi performansının ilişkisini ölçen genel bir yaklaşım sergilemişlerdir. Dolayısı ile iş zekası yatırımları hem iş süreci seviyesinde hem de organizasyonel seviyedeki performansa katkılarının olduğunu vurgulamışlardır.

Bu bilgiler ışığında bu çalışmada 1sıtma ve soğutma sistemleri satış ve satış sonrası hizmeti sunan bir işletmede yer alan farklı süreçlerin iş zekası uygulaması kapsamına alınması ve bu uygulamanın başarısı irdelenmiştir.

İşletmedeki iş zekası uygulamaları üç ana grupta toparlanmıştır. Bunlar proje yönetimi, stok yönetimi ve müşteri yönetimidir. İşletme idari yönetimi, bu üç konuda iş zekası uygulaması ile işlerinde daha iyi kararlar alabileceklerini, bunun için kullandıkları Kurumsal Kaynak Planlama (Enterprise Resource Planning -ERP) yazılımı ile entegre bir çözüm arayışı içinde olmuşlardır. $\mathrm{Bu}$ üç alanın seçilmesinin nedeni, bu alanların işletmenin ana faaliyet alanını temsil etmesi ile bu alanları izlemenin ve kontrol altında tutmanın diğer alanlara yapılacak olan yatırımdan daha önemli olmasıdır.

İşletme teklif usulü ile çalışma yapmakta ve verdiği teklifler kabul olması durumunda bunu bir proje şeklinde takip etmektedir. Proje Yönetimi kapsamında projelerin daha etkin bir şekilde takip ve koordinasyonu istenmektedir. Özellikle firmada küçüklü büyüklü yirmi beşe yakın proje aynı anda sürmektedir. Projeler bir teknik ve bir idari sorumlu tarafindan yürütülmektedir. Projelerin başarısı işletmenin karlılığını direkt olarak etkilediği için projeler ile ilgili olarak takip edilmek istenen hususlar;

1. Proje zaman çizelgesine uyum,

2. Proje bütçesine uyum şeklindedir.

İşletme de teklif verdikleri ve kazandıkları projeleri zamanında yetiştirebilmek adına birçok malzeme stokta tutulmaktadır ve stok maliyetleri kontrol altına alınmak istenmektedir. $\mathrm{Bu}$ kapsamda takip edilmek istenen hususlar; 
1. Stok maliyetleri,

2. Stok devir hızıdır.

Müşteriler ile ilişkiler işletmenin bir sonraki dönemde kazancını önemli ölçüde etkilemektedir. Bunun için her bir müşterinin bilgileri ve ilgili müşteriye hangi ürünün satıldığı, ürünü ile ilgili şikayetleri ve bu şikayetlere nasıl bir çözüm bulundu gibi birtakım bilgiler farklı sistemlerde veya bazıları da kâğıt ortamında tutulmaktadır. Bu kapsamda takip edilmek istenen hususlar ise;

1. Müşterideki ürünler ve ürünlerin bakım zamanları

2. Müşteri şikayetleri ve yapılan işlemlerdir.

İş zekası uygulaması olarak baktığımızda en büyük beklenti, bir konu hakkında bilgi alındıktan veya bilgiye ulaşıldıktan sonra ilgili bilginin detayına inerek analiz etmek şeklindedir. Bunun amacı bilgilere farklı sistemlerdeki raporlar yerine tek bir merkezden ve portalden erişim sağlanmak istenmesidir. Ayrıca her bir konu ile ilgili olarak iki istek görünmesine rağmen alt detayında "derinlemesine (drill down)" inceleme şeklinde bir bilgi istenmesinden dolayı çok farklı veriye erişim sağlanması gerekmektedir. Uygulamanın altyapısında, mevcut sistemden veriler bir ETL yazılımı ile alınıp OLAP veri tabanına aktarılarak tutulmaktadır. $\mathrm{Bu}$ aktarımlar, her akşam otomatik olarak yapılmaktadır. İlerleyen zamanda günde iki defa, gün ortasında ve akşam olacak şekilde yapılması planlanmaktadır. Ardından önyüzde ise veri analizi için bir uygulama yer almaktadır. İşletme için geliştirilen uygulamanın ekran görüntülerinden bir kısmı Şekil 7'de yer almaktadır.

Şekil 7: İş Zekası Uygulamasından Örnek Ekranlar

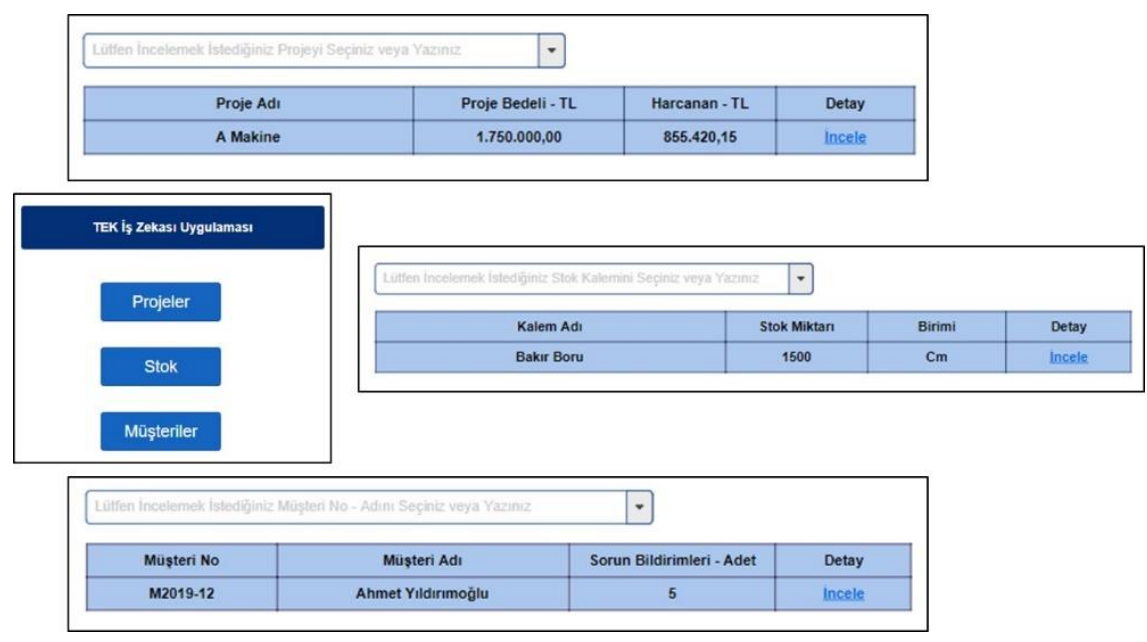


Uygulama kapsamında belirlenen üç gruptan projeler, stok ve müşteriler kısmından her bir uygulamanın alt detayındaki sorgulama kısımlarına ulaşılabilmektedir. Sorgulamanın yapılmasının ardından incele kısmı ile her bir sorgunun altında yer alan farklı bilgiye ulaşılmaktadır. Ulaşılan bilgiler zaman bazında detaylandırılmaktadır. Özetle, inceleme aşağıya doğru ilgili sorgunun detayına inilerek derinlemesine yapılabilmektedir.

İş zekası oluşturma sürecinde her bir alan ile ilgili olarak ihtiyaç sahibi birimler ile öncelikle ne tür sorular sorduklarını ve bu soruların cevaplarını işletme içindeki farklı kaynaklardan nasıl elde ettikleri belirlenmiştir. Ardından bu sorular daha da detaylandırılmış ve bunlar ile ilgili olarak her bir süreçte işletmenin yöneticilerini uyaracak anahtar performans indikatörleri (Key Performance Indicator) belirlenmiş ve bunlar uygulamaya alınmıştır. Ayrıca, uyarı mekanizmaları ve istediklerinde veriden aşağıya gidebilecekleri mekanizmalar yapılmıştır. Williams ve Williams (2003) işletmeler iş zekası uygulamalarını yönetim süreçlerini, operasyonel süreçlerini veya her ikisini iyileştirmek için uygulamaya alırlar şeklinde açıklamıştır. İş zekasının işletmeye katkısının iş zekası firsat analizi, iş zekası kullanım seviyesi analizi, süreç mühendisliği analizi, geri kazanım analizi ve değişim analizi gibi analizler ile ölçülebileceğini aktarmışlardır. Bu çalışmada yer alan işletme de aynı şekilde hem yönetim hem de operasyonel süreçlerinde iyileştirme yapmak istemiştir.

İşletmede geliştirilmiş olan iş zekası uygulaması aşağıdaki değerlendirme kriterleri ışığında irdelenmiştir. Bu değerlendirme kriterleri ilk aşamada farklı çalışmalar incelenerek firma için en uygun olan kriterler firma personeli ile beraber seçilmiştir. Kriterler daha çok iş zekasının kullanılabilirliği, güvenilirliği ve işletmeye katkıları üzerinde yoğunlaşmıştır. $\mathrm{Bu}$ değerlendirme yapılırken firmadaki iş zekasını geliştirmiş olan birim ile beraber ve ilgili yöneticilerin katılımı ile bir değerlendirme yapılmıştır. Değerlendirme kapsamında her bir kriter 1-5 arası bir puan almıştır. 5 en yüksek puandır. 1-5 arası puan verilirken ilgili kriterin olgunluğuna bakılmıştır. Değerlendirme sonucu Tablo 2'de yer almaktadır. İlk aşamada bu kriterleri değerlendirme ekibinde yer alan her üyenin tek başlarına yapmaları istenmiş ve ardından bir araya gelinerek tüm işletme için bu değerlendirme yapılmıştır. Tablo 2'de yer alan sonuçlar tüm işletme için olan değerlendirme sonuçlarıdır. Her bir kriter incelenirken iş zekası uygulamasını kullanan kişiler, bölümler, uygulamanın içeriği, yöneticilerin kullanımı gibi birçok husus ele alınmıştır.

Tablo 2: İş Zekası Uygulaması Sonuçları Değerlendirmesi 


\begin{tabular}{|l|l|c|c|c|}
\hline $\begin{array}{l}\text { Sıra } \\
\text { No }\end{array}$ & $\begin{array}{l}\text { İş Zekası Uygulamasının } \\
\text { Değerlendirme Kriterleri }\end{array}$ & $\begin{array}{c}\text { Aldığı Puan } \\
\text { (1: En Düşük 5: } \\
\text { En Yülksek) }\end{array}$ & Ağırlık & $\begin{array}{c}\text { Ağırlıklı } \\
\text { Puan }\end{array}$ \\
\hline 1 & Kullanım Kolaylığı & 4 & 0,05 & 0,2 \\
\hline 2 & Kullanıcı ile Etkileşimi & 3 & 0,05 & 0,15 \\
\hline 3 & İçeriğinin Çeşitliliği & 5 & 0,05 & 0,25 \\
\hline 4 & $\begin{array}{l}\text { Hızlı ve Detaya İnen } \\
\text { Sorgulamalar }\end{array}$ & 4 & 0,10 & 0,4 \\
\hline 5 & Verilerin Güncelliği & 3 & 0,15 & 0,45 \\
\hline 6 & Verilerin Güvenilirliği & 3 & 0,15 & 0,45 \\
\hline 7 & Sunduğu Bilginin Önemi & 4 & 0,10 & 0,4 \\
\hline 8 & İlgili Birime Katkısı & 4 & 0,15 & 0,6 \\
\hline 9 & İşletmeye Katkıs1 & 4 & 0,15 & 0,6 \\
\hline 10 & İşletme Süreçlerini Kapsaması & 3 & 0,05 & 0,15 \\
\hline & Toplam Puan & & & $\mathbf{3 , 6 5}$ \\
\hline
\end{tabular}

Tablo 2'den görüleceği üzere kriterlerden işletme için en önemlilerinin ağırlıklarına baktığımızda görebileceğimiz gibi veri ile ilgili olanlar; verilerin güncelliği ve güvenilirliği ile ilgili birime ve işletmeye katkısı olanlardır. Toplam sonuca baktığımız da ise uygulamaya alınan iş zekası 3,65 gibi bir puan elde etmiştir.

Yazılımların olgunluk seviyelerini, 1) Başlangıç 2) Tekrarlanabilir 3) Tanımlanmış 4) Yönetilebilen 5) Optimize edilmiş şeklinde tanımladığımızda bu uygulama 3,65 puanı ile tanımlanmış ile yönetilebilen arasinda bir yere oturmaktadir.

$\mathrm{Bu}$ çalışmanın yanı sıra Tablo 2'de yer alan 8 ve 9 nolu kriterlerin uygulamaya alındıkları alanlarda ve genel olarak işletmeye katkısının detayına inilmiş ve buradaki kazanımların neler olduğu ile ilgili çalışmalar yapılmıştır. Bunlar; operasyonel işleri yaparken sağladığı katkı olarak veriye daha hızlı bir şekilde erişim sağlandığı için uygulanan birimdeki veriyi görme açısından bir fayda sağlamıştır. Eskiden farklı ortamlarda aranan veri bir arada görülmeye başlanmış ve operasyonel ve yönetimsel kararlar daha sağlıklı alınmaya başlamıştır. Müşteri, stok ve projeler ile ilgili analizler daha hızlı bir şekilde yapılmaya başlanmıştır. Yapılan yatırımın getirisini ölçmek şu aşamada net olarak mümkün olmasa da ilerleyen zaman zarfında bu kazanımların projeleri daha iyi yönetebilme, stoktaki malzemeleri daha iyi takip edebilme ve müşterileri daha iyi analiz edebilme imkânı sağladığından dolayı, bu da artan satış ve müşteri memnuniyeti olarak dönmesi beklenmektedir. 


\section{Sonuç}

Kararlarımızın temeli veridir. Bu veriye direkt olarak erişmek her zaman doğru yolu göstermeyebilir. İşte bu durumlarda veri madenciliği ve iş zekası teknikleri bizi yönlendirmektedir. Kullanıcılar veriye farklı bakış açılarından bakabilmeli, veriden daha detaylı veriye ulaşabilmeli ve gelecek ile ilgili yorumlar yapabilmelidir. Bu çalışmaları son kullanıcıların yapabilmesi için bilişim personelinden destek almaları gerekmektedir. Ancak, bilişim personelinin iş yükü, yetişemeyecekleri kadar hızlı bir şekilde artmaktadır. Bu açığı gidermenin bir yöntemi de son kullanıcılara kendi raporlarını geliştirebilecekleri ara katman bir ortam sunmaktan geçmektedir. Bunu sağlayan iş zekası çözümleri büyük önem arz etmektedir. En küçük işletmeden en büyük işletmeye kadar, farklı farklı sektördeki işletmeler üretmiş oldukları veriden veya farklı kurum ve kuruluşların üretmiş olduğu verileri kullanarak kendileri veya başka kişileri yönlendirmek amacı ile iş zekası uygulamalarını kullanmaktadır.

Çalışma kapsamında yer alan işletme ilk aşamada iş zekası uygulamasından beklediği faydayı maksimize etmek için hedefini spesifik olarak belirlemiş ve bu hedefe ulaşmak için 3 süreç belirlemiştir. İşletmenin bu verilerden bir sonraki adımda iş analitiği şeklinde veri madenciliği ile ilgili analizlere ağırlık vererek stok, müşteriler ve projeler ile ilgili gidişatı daha iyi belirleyebilmesi açısından öngörüsel analizler yapması gerekecektir.

İlerleyen zaman zarfında iş zekası çözümleri artık otomatik olarak veri analizi yapabilecek yapıda olacaktır. Bunun için öncelikle, ne yapılmak istenmektedir? sorusuna cevap verildikten sonra sistem, nasıl yapılacağ1 kısmını, kendi içerisinde yer alan uygun olan modeli bulup uygun veri seti ile çalıştıracaktır. Bunun için veri ihtiyacını online veri ambarı veya operasyonel sistemlerden elde edecektir. Elde ettiği sonuçlara göre de sistemlerdeki parametreler de oynamalar yaparak en optimum sonuca ulaşmaya çalışacak ve elde ettiği sonucu uygulamaya geçirebilecektir. Kendi kendine öğrenen ve gerekli düzenlemeleri yapabilen iş zekası çözümleri geleceği şekillendirecektir. İlerleyen zamanda sistemler kendi başlarına süreçlerde kullanılmak yerine iş zekası çözümleri, sistemlerin kendi içinde bir çözüm merkezi olarak gelecektir.

\section{Kaynaklar}

Chen, H., Chiang, R. H. ve Storey, V. C. (2012). Business Intelligence and Analytics: From Big Data to Big Impact. MIS Quarterly, 36(4), s.1165-1188. 
Codd, E. F., Codd, S. B. ve Salley, C. T. (1993). Providing OLAP (On-Line Analytical Processing) to User-Analysts: An IT Mandate. Sunnyvale: E. F. Codd and Associates.

Çelebi, H. ve Çakmak, A. F. (2019). Veri Ambarı Projelerinde ETL Performansını Etkileyen Faktörlerin Belirlenmesi. Selçuk Üniversitesi Sosyal Bilimler Meslek Yüksekokulu Dergisi, 22(2), s.965-990.

Çetin, G., Tanrı̈ver, Ö.Ö. (2020). Personel İş Zekası Sistemi ve Veri Madenciliği ile Personel Memnuniyetinin Ölçülmesi. Avrupa Bilim ve Teknoloji Dergisi, Özel Sayı, s.323-334.

Datawarehouse, http://www.datawarehouse4u.info/ (Erişim Tarihi: 20.04.2020)

Daş, R., Türkoğlu, İ. ve Poyraz, M. (2006). Genetik Algoritma Yöntemiyle Internet Erişim Kayıtlarından Bilgi Çıkarılması. SAÜ Fen Bilimleri Enstitüsü Dergisi, 10(2), s.67-72.

Dondurmac1, G. A. ve Çınar, A. (2014). Finans Sektöründe Veri Madenciliği Uygulaması. Akademik Sosyal Araştırmalar Dergisi, 2(1), s.258-271.

Eder, F. ve Koch, S. (2018). Critical Success Factors for the Implementation of Business Intelligence Systems. International Journal of Business Intelligence Research, 9(2), s.27-46.

Elbashir, M. Z., Collier, P. A. ve Davern, M. J. (2008). Measuring The Effects of Business Intelligence Systems: The Relationship Between Business Process and Organizational Performance. International Journal of Accounting Information Systems, (9), s.135-153.

Emre, İ. E. ve Selçukcan Erol, Ç. (2017). Veri Analizinde İstatistik mi Veri Madenciliği mi? Bilişim Teknolojileri Dergisi, 10(2), s.161-167.

Fayyad, U., Shapiro, G. P. ve Smyth, P. (1996). From Data Mining to Knowledge Discovery in Databases. AI Magazine - American Association for Artificial Intelligence -AAAI, 17(3), s.37-54.

Gartner, Market Share: Analytics and Business Intelligence, Worldwide, 2019 (2020)

Gültekin, H.B., Biroğul, S. (2020). Reviewing The Effect of Business Intelligence on Decision Support Process: An Application on The Finance Sector. Bilişim Teknolojileri Dergisi, 13(2), s.197-206. 
Hackathorn, R. (2004). The BI Watch: Real-Time to Real-Value. DM Review, s.1-4.

Han, J., Kamber, M., Pei, J. (2012). Data Mining Concepts and Techniques (Third Edition). Elsevier.

Howson, C. (2014). Successful Business Intelligence - Unlock the Value of BI \& Big Data (Second Edition). New York: McGraw-Hill.

Koyuncugil, A. ve Özgülbaş, N. (2009). Veri Madenciliği: Tıp ve Sağlık Hizmetlerinde Kullanımı ve Uygulamaları. Bilişim Teknolojileri Dergisi, 2(2), s.21-32.

Lim, E.-P., Chen, H. ve Chen, G. (2013). Business Intelligence and Analytics: Research Directions. ACM Transactions on Management Information Systems, 3(4), s.1-10.

Loshin, D. (2013). Business Intelligence The Savvy Manager's Guide (Second Edition). Waltham: Elsevier.

Lönnqvist, A. ve Pirttimäki, V. (2006). The Measurement of Business Intelligence. Information Systems Management, 23(1), s.32-40.

Luhn, H. P. (1958). A Business Intelligence System. IBM Journal, s.314319.

Matheus, C. J., Chan, P. K. ve Shapiro, G. P. (1993, December). Systems for Knowledge Discovery in Databses. IEEE Transaction on Knowledge and Data Engineering, 5(6), s.903-913.

Power, D. J. (2007). A Brief History of Decision Support Systems. DSSResources.com (Erişim Tarihi: 20.04.2020).

Simovits, M. ve Forsberg, T. (1995-1996). Busineess Intelligence and Information Warfare on the Internet. NordSec 1995 ve Infosec 1996.

Terzi, M. (2019, Mayıs). Türkiye'de Sağlık Sektöründe Veri Madenciliği Kullanım Alanları. Black Sea Journal of Health Science, 2(2), s.4548.

Vercellis, C. (2009). Business Intelligence: Data Mining and Optimization for Decision Making. Milano: Wiley.

Williams, S. ve Williams, N. (2003). The Business Value of Business Intelligence. Business Intelligence Journal, 101, s.32-43.

Yeoh, W. ve Koronios, A. (2010). Critical Success Factors for Business Intelligence Systems. Journal of Computer Information Systems, 50(3), s.23-32. 
Yeoh, W. ve Popovic, A. (2015). Extending the Understanding of Critical Success Factors for Implementing Business Intelligence Systems. Journal of the Association For Information Science And Technology, 67(1), s.134-147. 